\title{
Effect of Heat Stress on Developmental Competence of In Vitro Matured Oocytes of Camelus Dromedaries with Different Qualities
}

\author{
G. Ashour ${ }^{1}$, Ashraf El-Sayed ${ }^{1,3}$, M. Khalifa ${ }^{4}$ and Nasser Ghanem $^{1,2 *}$ \\ ${ }^{I}$ Department of Animal Production, Faculty of Agriculture, Cairo University, Giza, Egypt \\ ${ }^{2}$ Cairo University Research Park (CURP), Faculty of Agriculture, Cairo University, Giza, Egypt \\ ${ }^{3}$ King Abdulaziz University, Jeddah, Kingdom of Saudi Arabia \\ ${ }^{4}$ Central Laboratory for Research, MSA University, Giza, Egypt \\ *Corresponding author's Email: nassergo@agr.cu.edu.eg; (DORCiD: 0000-0002-0480-0959
}

\begin{abstract}
The deleterious effect of heat stress on cumulus-oocytes complexes (COCs) competence is well recognized in different livestock species. Therefore, the present study aimed to investigate the effect of physiologically relevant heat stress on the developmental competence of camel COCs during in vitro maturation (IVM). A total of 1548 COCs were divided into six groups in this study. The groups were named $\mathrm{K} 1$ and $\mathrm{K} 2$ representing good and lowquality COCs incubated at $38.5^{\circ} \mathrm{C}$ for 30 hours. While $\mathrm{K} 3$ and $\mathrm{k} 4$ represent good and low-quality COCs exposed to $41^{\circ} \mathrm{C}$ for the first 6 hours of IVM. Finally, K5 and k6 represent the groups of good and low-quality COCs exposed to $42^{\circ} \mathrm{C}$ for the first 6 hours of IVM. After exposure of COCs to heat stress at $41^{\circ} \mathrm{C}$ and $42^{\circ} \mathrm{C}$ during the first 6 hours of in vitro maturation, the COCs were incubated at $38.5^{\circ} \mathrm{C}$ for 24 hours of IVM. The in vitro matured COCs were activated to cleave using ethanol followed by $4 \mathrm{mM}$ 6-DMAP and developed embryos were cultured in vitro for 7 days post parthenogenetic activation. The results of this study indicated that heat stress at $42^{\circ} \mathrm{C}$ significantly decreased the $\mathrm{Pb}$ (polar body) extrusion rate in $\mathrm{K} 4$ and $\mathrm{K} 6$, compared to other groups. Additionally, the embryo cleavage rate was significantly lower for good and low-quality oocytes exposed to heat stress $(\mathrm{K} 2, \mathrm{~K} 3, \mathrm{~K} 4, \mathrm{~K} 5$, and K6), compared to good quality COCs of the control group (K1). The cleavage rate was lower for low quality (K2; 63 $\pm 1.28)$ than good quality COCs $(\mathrm{K} 1 ; 53 \pm 1.85)$. The percentages of oocytes that developed to the blastocyst stage were lower for K2, K3, K4, K5, and K6 than K1. Moreover, the blastocyst rate was lower for K2 (9 \pm 0.22$)$ than K1 $(15 \pm 0.22)$. The results of this study indicated that exposure of camel oocytes to heat stress for 6 hours during in vitro maturation severely reduced extrusion of polar body, cleavage, and blastocyst rates. The low-quality camel COCs were reduced developmental capacity than good quality oocytes.
\end{abstract}

Keywords: Camel, Embryo development, Heat stress, Oocyte

\section{INTRODUCTION}

Nowadays, there has been concerted attention to global warming, especially in tropical and subtropical regions, due to the increased level of average air temperature during recent years (Rabie, 2020). Egypt is located in a subtropical climatic region, which encourages the adaptation to the extreme heat stress and drought of the desert. In this regard, the Arabian camel, known as Camelus dromedaries, has developed unique anatomical as well as physiological and biochemical characteristics (Hoter et al., 2019) to cope with such challenges. Camelus dromedarius is a source for meat, wool, and milk in desert areas heavily affected by the heat and shortage of feed and water (Yaqoob et al., 2017).

Camels' population in Egypt consists of 148060 animals contributing to approximately 36398 tons of meat (i.e., 1.7 of total meat production in Egypt, (FAO, 2015). In response to climatic change progress, there is a promising role for camels due to their high resistance to heat and arid conditions. The reproductive performance of Camelus dromedaries is considered one of the most important factors affecting camel productivity (Tibary and El Allali, 2020). Heat stress has negative effects on the reproductive efficiency of dairy cows. It has been reported that heat stress could increase ovarian inactivity, which is manifested by anestrous (Wolfenson et al., 2000; Oseni et al., 2003). The reduction in estradiol biosynthesis is the mechanism by which heat stress deteriorates ovarian follicle development and impaired expression of estrus (Badinga et al., 1993; Wolfenson et al., 1988). The ovarian follicles and their enclosed oocytes are highly sensitive to hyperthermia (Roth, 2017; Islam et al., 2018). (Camargo et al., 2019) stated that heat shock increases the proportion of apoptotic oocytes during in vitro maturation (Camargo et al., 2019). The findings of a recent study suggest that camel oocytes are less tolerant of the short acute heat shock, which is linked with reduced ooplasm diameter and maturation rate as well as increased incidence of chromosomal count abnormalities (Islam et al., 2018). In fact, the slow development of assisted reproductive technologies, such as Artificial Insemination (AI), embryo transfer, and IVEP, represents a major obstacle in the wide application of these techniques in Camelus dromedaries (Abdoon et al., 2014). P 
Parthenogenetic activation of the metaphase II oocytes in such species as camelids provides the chance to evaluate the development ability of oocytes without the need to an external factor (sperms). Therefore, the present study was carried out to examine the effect of heat stress during in vitro maturation on the developmental competence of camel oocytes with different morphological qualities up to the blastocyst stage after parthenogenetic activation.

\section{MATERIALS AND METHODS}

This study was carried out at the Central Laboratory for Research, MSA University, Egypt. All the employed reagents and media used in the current study were obtained from Sigma-Aldrich (St. Louis, MO, USA) otherwise, their incorporations were addressed.

\section{Ethical approval}

The current study does not require an ethical approval as the main materials are ovaries that collected from slaughtered animals in local abattoir according to Minister of Agriculture regulations.

\section{Experimental design}

The control groups $\mathrm{K}_{1}$ (control for the good morphological quality group) and $\mathrm{K}_{2}$ (control for the low morphological quality group) were subjected to an incubation temperature of $38.5^{\circ} \mathrm{C}$. The treated groups of good quality oocytes $\mathrm{K}_{3}$ and $\mathrm{K}_{4}$ were exposed to $41^{\circ} \mathrm{C}$ and $42^{\circ} \mathrm{C}$, respectively. The treated groups of low quality oocytes $\mathrm{K}_{5}$ and $\mathrm{K}_{6}$ were exposed to $41^{\circ} \mathrm{C}$ and $42^{\circ} \mathrm{C}$, respectively. The four treated groups (about 260 oocyte/group) were exposed to the assigned temperature for the first 6 hours of in vitro maturation, thereafter, the incubation temperature for all treatments decreased to $38.5^{\circ} \mathrm{C}$ for 24 hours until the end of IVM duration. Maturation rates of the $\mathrm{K}_{1}, \mathrm{~K}_{2}, \mathrm{~K}_{3}, \mathrm{~K}_{4}, \mathrm{~K}_{5}$, and $\mathrm{K}_{6}$ oocytes were estimated based on the expansion of cumulus cells and the $\mathrm{Pb}$ extrusion ratio, then all groups were subjected to parthenogenetic activation to follow up early embryo developmental rate until blastocyst stage.

\section{Procedures}

\section{Ovaries collection and oocytes recovery}

Camel ovaries were collected from nearby abattoirs. The collected ovaries were transported to the laboratory within 3 hours in pre-warmed $\left(30^{\circ} \mathrm{C}\right)$ physiological saline $(0.9 \% \mathrm{NaCl})$ supplemented with $(100 \mu \mathrm{g} / \mathrm{ml}$ streptomycin sulfate and $100 \mathrm{IU} / \mathrm{ml}$ penicillin). The collected ovaries were washed once in $70 \%$ ethanol and then three times in phosphate buffer saline supplemented with $(100 \mu \mathrm{g} / \mathrm{ml}$ streptomycin sulfate and $100 \mathrm{IU} / \mathrm{ml}$ penicillin). Cumulus-oocyte complexes (COCs) were aspirated from follicles 2-8 mm in diameter using a $10 \mathrm{~mL}$ disposable syringe with an 18-gauge needle. The recovered COCs were washed three times in Hepes-buffered Medium199 (22340; Gibco, UK) supplemented with $100 \mu \mathrm{g} / \mathrm{ml}$ streptomycin sulfate, $100 \mathrm{IU} / \mathrm{ml}$ penicillin, and 10\% inactivated fetal bovine serum (FBS). Cumulusoocyte complexes were classified into good (grade A and B) and low quality (grade C) based on morphological assessment. The assessment of oocyte quality was based on the number of cumulus cell layers and the homogeneity of cytoplasm (Mesbah et al., 2016).

\section{In vitro maturation of oocytes}

The in vitro maturation medium is a basic maturation medium (TCM199) supplemented with $20 \mu \mathrm{g} / \mathrm{mL}$ folliclestimulating hormone, $10 \% \mathrm{FBS}, 10 \mathrm{ng} / \mathrm{mL}$ epidermal growth factor, $100 \mu \mathrm{g} / \mathrm{ml}$ streptomycin sulfate, and $100 \mathrm{IU} / \mathrm{ml}$ penicillin. The COCs were washed twice in IVM medium according to the experiment design. A total of 25-30 COCs/well were cultured in $400 \mu \mathrm{l}$ of IVM medium overlaid with $400 \mu 1$ mineral oil in 4 well culture plate (Nunc, Denmark) under $5 \% \mathrm{CO}_{2}$ and humidified air for 30 hours. Examination of matured oocytes was performed after 30 hours of incubation and based on cumulus expansion and extrusion of the first polar body using Optica stereomicroscope (SZM-LED1, Italy) and Leica inverted microscope.

\section{Parthenogenetic activation and culture}

The matured oocytes were denuded by gentle repetitive pipetting in a $0.1 \%$ hyaluronidase solution (Irivine Scientific, CA 92705 USA). Cumulus-free oocytes were then incubated in TCM-199 containing 10\% FBS supplemented with 7\% ethanol for $7 \mathrm{~min}$ (Wani, 2007) in a dark chamber. Oocytes were then washed in TCM-199 with 10\% FBS, then transferred to $100-\mu \mathrm{L}$ micro-drops of $4 \mathrm{mM}$ 6-dimethylaminopurine (6-DMAP, D-2629), covered with mineral oil, and cultured in a humid atmosphere of $5 \% \mathrm{CO} 2$ at $38.5^{\circ} \mathrm{C}$ for 4 hours. After activation, activated oocytes were washed twice in the in vitro culture medium (Continuous Single Culture -NX Complete, cat no. 90168, Irivine Scientific, CA 92705 USA) placed into 4-well culture Plates (400 $\mu$ l culture media per well) under mineral oil in the humidified atmosphere of $5 \% \mathrm{CO} 2$ at $38.5^{\circ} \mathrm{C}$. Cleavage rate (2-8 cells) was recorded 48 hours after culture. The number of embryos developed to the blastocyst stage was assessed 7 days after in vitro culture. 


\section{Statistical analysis}

Experimental Statistical analysis for maturation rate (expansion level and extrusion of the polar body) and embryonic development rates were performed using a randomized complete block design with six replications for each group using the web Agri Stat Package. The treatment means were compared by the least significant difference (LSD) test as reported by Snedecor and Cochran (1994) using ASSISTAT software, version 7.7 beta freeware. P-value less than 0.05 was considered statistically significant.

\section{RESULTS AND DISCUSSION}

\section{Effect of heat stress on maturation rate of camel oocytes}

Climate change has raised tangible concerns about global warming representing a significant threat to the feasibility and sustainability of livestock farming worldwide, particularly in regions located in tropical and subtropical zones. Egypt is located in a subtropical area, where the intense heat stress of summer is accompanied by high ambient humidity. This issue worsens the situation and represents a constraint to farm animal welfare, productivity, and reproductive performance (Marai and Habeeb, 2010). In this regard, cumulus-oocyte complexes are highly affected when the female is exposed to environmental heat stress during follicular development, ovulation and in vivo events of oocyte maturation (Al-Katanani et al., 2002; Gendelman and Roth, 2012; Sadeesh et al., 2016).

There is a growing interest in establishing and improving assisted reproductive techniques, such as in vitro embryo production in camel. In addition, the in vitro maturation of oocyte is the key step for improving the success rate of in vitro embryo production in this species (Trasorras et al., 2013; Mesbah et al., 2016; Moulavi and Hosseini, 2018). Accordingly, cumulus expansion and extrusion of the first polar body are the main criteria used to evaluate the nuclear maturation of camel oocytes (Yaqoob et al., 2017; Saadeldin et al., 2019). The data of the current study indicated no change in the incidence of cumulus expansion in good quality COCs before $(92.98 \pm 0.95 \%)$ and after heat shock exposure at $41^{\circ} \mathrm{C}(93.61 \pm 1.32 \%)$ and $42^{\circ} \mathrm{C}(93.96 \pm 0.64 \%)$. However, the low quality COCs demonstrated no sign of cumulus expansion, which may be due to decreased number of cumulus layers in this quality category or low expression of TGF $\beta$ genes. In support to this idea, the lowest first polar body extrusion rate $(11.2 \% \pm 2.5 \%)$ was found in the group of camel oocytes treated with the inhibitor of the TGF $\beta$ pathway (SB-431542) which interferes with the activity of activin receptor-like kinases accompanied by no expansion of cumulus cells (Saadeldin et al., 2019).

The results of this study indicated that the heat stress has the same effect on both good and low-quality oocytes concerning nuclear maturation represented by $\mathrm{Pb}$ extrusion percentage and cytoplasmic maturation represented by cumulus expansion score. The cumulus expansion level was significantly higher in good quality oocyte groups K1 (P < $0.01,92.98 \pm 0.95 \%), \mathrm{K} 3(93.61 \pm 1.32 \%)$, and $\mathrm{K} 4(93.96 \pm 0.64 \%)$ compared to low quality oocyte groups of K2 (0\%), $\mathrm{K} 5(0 \%)$, and $\mathrm{K} 6(0 \%)$. Moreover, exposure of COCs to heat stress at $42^{\circ} \mathrm{C}$ significantly decreased the $\mathrm{Pb}$ ratio in $\mathrm{K} 4(\mathrm{P}$ $<0.01,20.73 \pm 0.49 \%)$ and $\mathrm{K} 6(20.30 \pm 0.52 \%)$ compared to the control K1 $(32.31 \pm 0.54 \%), \mathrm{K} 2(30.98 \pm 1.36 \%)$, and heat-stressed groups at $41^{\circ} \mathrm{C} \mathrm{K} 3(31.44 \pm 0.92 \%)$ and $\mathrm{K} 5(31.63 \pm 0.47 \%)$. Indeed, buffalo cumulus-oocyte complexes that were collected during hot season had a high percentage of arrested oocytes in metaphase I stage after in vitro maturation (Abdoon et al., 2014). Interestingly, bovine oocytes that have been exposed to heat shock at $40.0^{\circ} \mathrm{C}$ and $41.0^{\circ} \mathrm{C}$ recorded lower rates of nuclear and cytoplasmic maturation (Maya-Soriano et al., 2013). Similarly, El-Sayed et al. (2018) have indicated that exposure of buffalo COCs to heat shock reduced the percentage of in vitro matured oocytes at temperature of $39.5^{\circ} \mathrm{C}$ and $40.5^{\circ} \mathrm{C}$ compared with that of non-treated control group $\left(38.5^{\circ} \mathrm{C}\right)$.

\section{Effect of heat stress on the development rate of in vitro produced camel embryos from oocytes with different} quality

After parthenogenesis, development rate until 2-8 cells embryo was lower $(\mathrm{P}<0.01)$ for good $(\mathrm{K} 3=50 \pm 0.92$ and $\mathrm{K} 4=55 \pm 1.58)$ and low $(\mathrm{K} 5=45 \pm 1.28$ and $\mathrm{K} 6=27 \pm 0.56)$ quality oocytes exposed to heat stress, compared with control K1 $(63 \pm 1.28)$ and $\mathrm{K} 2(53 \pm 1.85)$. Moreover, development rate up to 2-8 cells embryo was lower $(\mathrm{P}<0.01)$ for low quality oocytes exposed to heat stress K5 $(45 \pm 1.28)$ and K6 (27 \pm 0.56$)$ compared with good quality oocytes exposed to the same heat stress K3 $(50 \pm 0.92)$ and K4 $(55 \pm 1.58)$. The development rate was significantly lower for control low quality $(\mathrm{P}<0.01,53 \pm 1.85)$ compared to the control good quality oocytes $(63 \pm 1.28)$. Bovine oocytes exposed to heat stress at $40.0^{\circ} \mathrm{C}$ and $41.0^{\circ} \mathrm{C}$ reduced in vitro embryo development rate (Maya-Soriano et al., 2013). Saadeldin et al. (2018) demonstrated that camel oocytes exposed to short acute heat shock at $45^{\circ} \mathrm{C}$ for 2 , showed reduction in maturation rate, linked with decreased ooplasmic diameter and increased percentage of chromosomal abnormalities. 
The percentage of oocytes developed to the blastocyst stage was significantly lower for good quality oocytes exposed to heat stress K3 and K4 ( $\mathrm{P}<0.01$ ), compared with control K1. Blastocyst rate was significantly lower for low quality oocytes exposed to heat stress $42^{\circ} \mathrm{C} \mathrm{K6}\left(\mathrm{P}<0.01\right.$ ), compared with low quality oocytes exposed to $41^{\circ} \mathrm{C} \mathrm{K} 5$ and control low quality oocytes $\mathrm{K} 2(0,3 \pm 0.22$, and $9 \pm 0.22$, respectively). Blastocyst rate was lower for control low quality oocytes $\mathrm{K} 2$ compared with control good quality oocytes $\mathrm{K} 1$ ( $\mathrm{P}<0.01,9 \pm 0.22$, and $15 \pm 0.22$, respectively). There was no significant difference between good quality oocytes exposed to $42^{\circ} \mathrm{C} \mathrm{K} 4$ and low-quality oocytes exposed to $41^{\circ} \mathrm{C}(2$ \pm 0.21 and $3 \pm 0.22$, respectively). In support to previous observation, experimental exposure of COCs to heat shock during the maturation has revealed reduced cleavage rate as well as blastocyst development (Edwards and Hansen, 1997). In addition, in vivo experiments have reported reduced pregnancy rate by $25 \%$ for each ${ }^{\circ} \mathrm{C}$ elevation in body temperature, which is due to the negative impact of heat stress on preimplantation development embryos (Nabenishi et al., 2012). Recently, heat shock at $40^{\circ} \mathrm{C}$ for $24 \mathrm{~h}$ during IVM of bovine COCs had no effect on $\mathrm{Pb}$ extrusion rate however; it reduced the rate of embryo cleavage and blastocyst development (Pöhland et al., 2020).

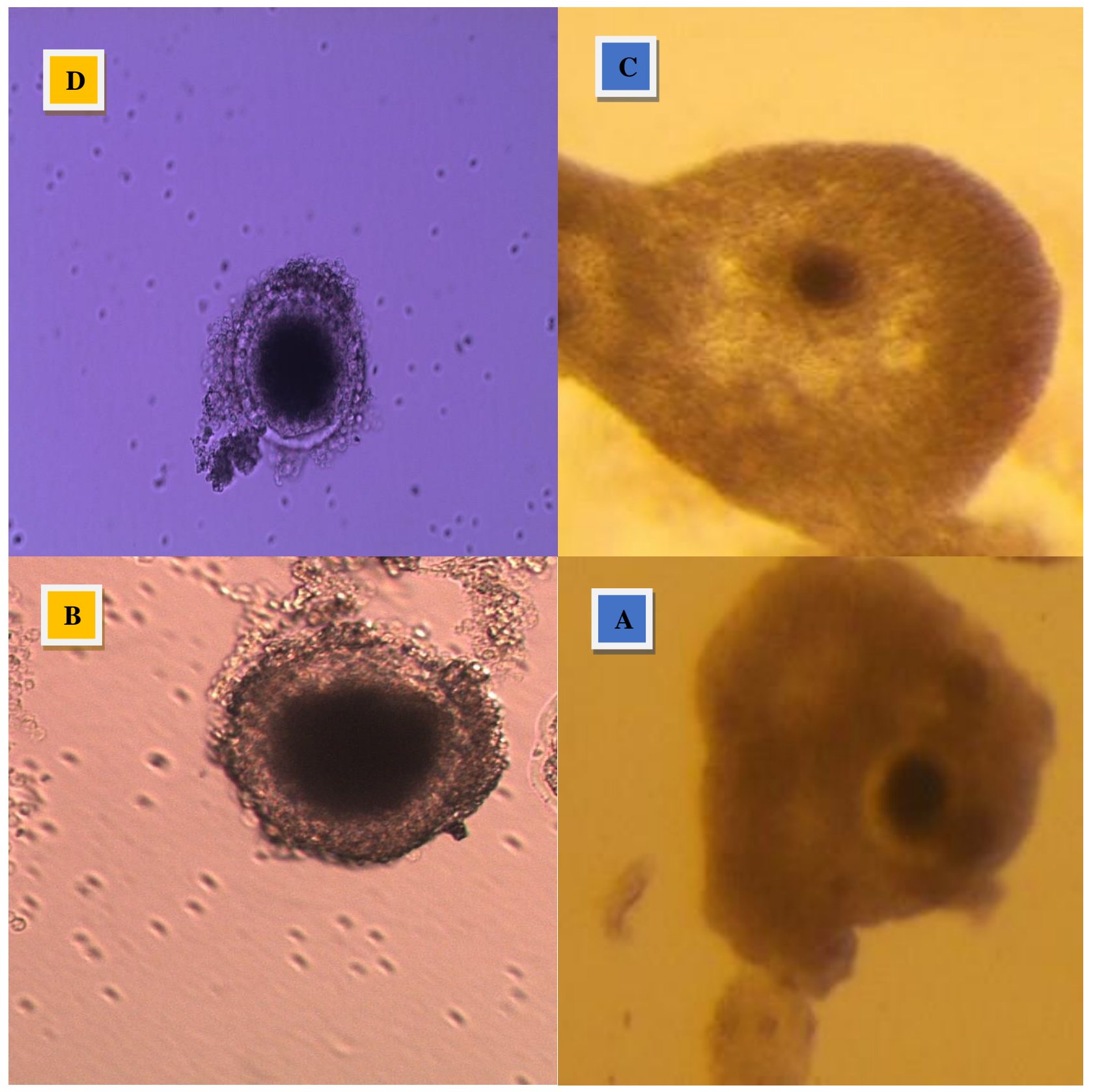

Figure 1. Immature and mature oocytes with different quality. A: Immature good quality oocyte. B: Immature low quality oocyte. C: Mature good quality oocyte. D: Mature low quality oocyte 


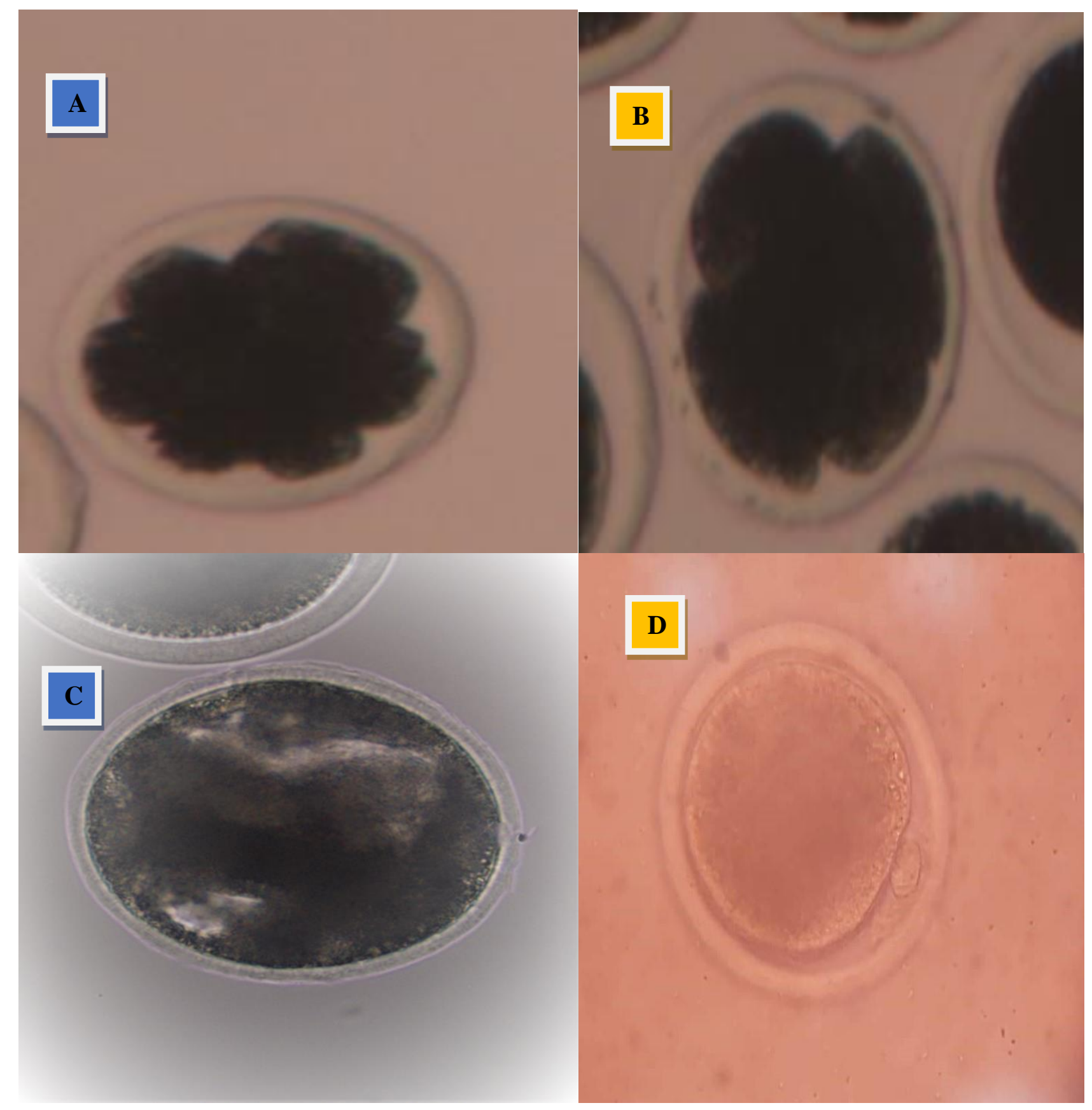

Figure 2. Polar body and different developmental stages of camel embryos. A: Blocked embryo. B: Four cell stage embryo. C: Blastocyst. D: Mature oocyte with polar body.

Table 1. Effect of heat stress on developmental rate of in vitro produced camel embryos from oocytes with different quality

\begin{tabular}{lccccc}
\hline group & Oocytes $(\mathbf{n})$ & $\begin{array}{c}\text { Cumulus } \\
\text { expansion }(\%)^{*}\end{array}$ & $\begin{array}{c}\text { Matured oocytes } \\
(\mathbf{n}) * *\end{array}$ & $\begin{array}{c}\text { Polar body extrusion } \\
(\%) * * *\end{array}$ & Polar body (n) \\
\hline $\mathrm{K} 1$ & 266 & $92.98 \pm 0.95^{\mathrm{a}}$ & $247 \pm 6.34^{\mathrm{a}}$ & $32.31 \pm 0.54^{\mathrm{a}}$ & $86 \pm 2.25 \mathrm{a}$ \\
$\mathrm{K} 2$ & 273 & $0^{\mathrm{b}}$ & $0^{\mathrm{b}}$ & $30.98 \pm 1.36^{\mathrm{a}}$ & $87 \pm 2.77 \mathrm{a}$ \\
$\mathrm{K} 3$ & 230 & $93.61 \pm 1.32^{\mathrm{a}}$ & $216 \pm 4.03^{\mathrm{a}}$ & $31.44 \pm 0.92^{\mathrm{a}}$ & $72 \pm 1.21 \mathrm{~b}$ \\
$\mathrm{~K} 4$ & 275 & $93.96 \pm 0.64^{\mathrm{a}}$ & $258 \pm 7.01^{\mathrm{a}}$ & $20.73 \pm 0.49^{\mathrm{b}}$ & $57 \pm 1.59 \mathrm{c}$ \\
$\mathrm{K} 5$ & 282 & $0^{\mathrm{b}}$ & $0^{\mathrm{b}}$ & $31.63 \pm 0.47^{\mathrm{a}}$ & $89 \pm 2.47 \mathrm{a}$ \\
$\mathrm{K} 6$ & 222 & $0^{\mathrm{b}}$ & $0^{\mathrm{b}}$ & $20.30 \pm 0.52^{\mathrm{b}}$ & $45 \pm 0.85 \mathrm{c}$ \\
\hline
\end{tabular}

$\overline{\mathrm{a}, \mathrm{b} ;}$ Means within a column with different superscripts differ significantly $(\mathrm{P}<0.01)$. *Evaluated after $30 \mathrm{~h}$. **Based on cumulus cells expansion. ***Based on polar body extrusion. $\mathrm{K} 1$ : Good quality oocytes incubated at $38.5^{\circ} \mathrm{C}$ for 30 hours; K2: Low quality oocytes incubated at $38.5^{\circ} \mathrm{C}$ for 30 hours; K3: Good quality oocytes exposed to $41^{\circ} \mathrm{C}$ for the first 6 hours of maturation; K4: Good quality oocytes exposed to $42^{\circ} \mathrm{C}$ for the first 6 hours of maturation; K5: Low quality oocytes exposed to $41^{\circ} \mathrm{C}$ for the first 6 hours of maturation; K6: Low quality oocytes exposed to $42^{\circ} \mathrm{C}$ for the first 6 hours of maturation. n: Number 
Table 2. Effect of heat stress on development rate of in vitro produced camel embryos from oocytes with different quality

\begin{tabular}{lcccc}
\hline group & Oocytes $(\mathbf{n})$ & Development 2-8 cells $(\mathbf{n})^{*}$ & Blastocyst $(\mathbf{n}) * *^{\mathrm{a}}$ & blocked embryos $(\mathbf{n}) * * *^{*}$ \\
\hline K1 & 266 & $63 \pm 1.28^{\mathrm{a}}$ & $15 \pm 0.22^{\mathrm{a}}$ & $48 \pm 1.06^{\mathrm{e}}$ \\
K2 & 273 & $53 \pm 1.85^{\mathrm{c}}$ & $9 \pm 0.22^{\mathrm{b}}$ & $44 \pm 1.36^{\mathrm{d}}$ \\
K3 & 230 & $50 \pm 0.92^{\mathrm{b}}$ & $6 \pm 0^{\mathrm{c}}$ & $44 \pm .92^{\mathrm{c}}$ \\
K4 & 275 & $55 \pm 1.58^{\mathrm{bc}}$ & $2 \pm 0.21^{\mathrm{de}}$ & $53 \pm 1.45 \mathrm{a}^{\mathrm{b}}$ \\
K5 & 282 & $45 \pm 1.28^{\mathrm{d}}$ & $3 \pm 0.22^{\mathrm{d}}$ & $42 \pm 1,06^{\mathrm{b}}$ \\
K6 & 222 & $27 \pm 0.56^{\mathrm{e}}$ & $0^{\mathrm{e}}$ & $27 \pm 0.56^{\mathrm{a}}$ \\
\hline
\end{tabular}

$\overline{a, b, c, d, e ;}$ Means within a column with different superscripts differ significantly $(\mathrm{P}<0.01)$. *Calculated as \% of total oocytes. **Calculated as \% of cleaved embryos. $* * *$ Calculated as $\%$ of cleaved embryos. K1: Good quality oocytes incubated at $38.5^{\circ} \mathrm{C}$ for 30 hours; K2: Low quality oocytes incubated at $38.5^{\circ} \mathrm{C}$ for 30 hours; $\mathrm{K} 3$ : Good quality oocytes exposed to $41^{\circ} \mathrm{C}$ for the first 6 hours of maturation; K4: Good quality oocytes exposed to $42^{\circ} \mathrm{C}$ for the first 6 hours of maturation; K5: Low quality oocytes exposed to $41^{\circ} \mathrm{C}$ for the first 6 hours of maturation; K6: Low quality oocytes exposed to $42^{\circ} \mathrm{C}$ for the first 6 hours of maturation. $\mathrm{n}$ : Number

\section{CONCLUSION}

The results of this study indicated that the exposure of camel oocytes to heat stress during the first 6 hours of in vitro maturation could severely affect their developmental competence. The low morphologically quality COCs have no signs of cumulus expansion and had lower development competence than good quality after exposure to in vitro heat shock.

\section{DECLARATIONS}

\section{Authors' contribution}

All authors have contributed equally in laboratory works, the experimental design, writing, and revision of the manuscript.

\section{Competing interests}

All authors declare no competing interests that might interfere with the data provided in the current manuscript.

\section{REFERENCES}

Abdoon AS, Gabler C, Holder C, Kandil OM, and Einspanier R (2014). Seasonal variations in developmental competence and relative abundance of gene transcripts in buffalo (Bubalus bubalis) oocytes. Theriogenology, 82(8): 1055-1067. DOI: https://www.doi.org/10.1016/j.theriogenology.2014.07.008

Al-Katanani YM, Paula-Lopes FF, and Hansen PJ (2002). Effect of Season and Exposure to Heat Stress on Oocyte Competence in Holstein Cows. Journal of Dairy Science, 85(2): 390-396. DOI: https://www.doi.org/10.3168/jds.S0022-0302(02)74086-1

Badinga 1, Thatcher WW, Diaz T, Drost M, and Wolfenson D (1993). Effect of environmental heat stress on follicular development and steroidgenesis in lactating Holstein cows. Theriogenology, 39: 797. DOI: https://www.doi.org/10.1016/0093$\underline{691 X(93) 90419-6}$

Camargo LSA, Costa FQ, Munk M, Sabine WV, Raquel VS, Bruno CC, Paulo HCJr, Alex CV, Luiz AGN, Joao HMV et al. (2019). Contrasting effects of heat shock during in vitro maturation on development of in vitro-fertilized and parthenogenetic bovine embryos. Reproduction Domestic Animals, pp. 1-9. DOI: https://www.doi.org/10.1111/rda.13544

Edwards JL, and Hansen PJ (1997). Differential responses of bovine oocytes and preimplantation embryos to heat shock. Molecular Reproduction and Development, 46(2): 138-145. DOI: https://www.doi.org/10.1002/(SICI)1098-2795(199702)46:2<138::AIDMRD4>3.0.CO;2-R

El-Sayed A, Nagy R, El-Asheeri A, and Eid L (2018). Developmental and molecular responses of buffalo (Bubalus bubalis) cumulusoocyte complex matured in vitro under heat shock conditions. Zygote, 26(2): 177-190. DOI: https://www.doi.org/10.1017/S0967199418000072

Food Agriculture Organization (FAO) (2015). Climate change and food systems: global assessments and implications for food security and trade. Food Agriculture Organization of the United Nations, Available at: http://www.fao.org/3/a-i4332e.pdf

Gendelman M, and Roth Z (2012). Seasonal effect on germinal vesicle-stage bovine oocytes is further expressed by alterations in transcript levels in the developing embryos associated with reduced developmental competence. Biology of Reproduction, 86(1): 1-9. DOI: https://www.doi.org/10.1095/biolreprod.111.092882

Hoter A, Rizk S, and Naim HY (2019). Cellular and Molecular Adaptation of Arabian Camel to Heat Stress. Front. Genet, $10: 588$. DOI: https://doi.org/10.3389/fgene.2019.00588.

Islam M Saadeldin, Ayman Abdel-Aziz Swelum, Mona Elsafadi, Amer Mahmood, Musaad Alfayez, and Abdullah N Alowaimer (2018). Differences between the tolerance of camel oocytes and cumulus cells to acute and chronic hyperthermia, Journal of Thermal Biology, 47: 47-54. DOI: https://www.doi.org/10.1016/j.jtherbio.2018.03.014

Marai IFM, and Habeeb AAM (2010). Buffalo's biological functions as affected by heat stress - A review. Livestock Science, 127(2): 89-109. DOI: https://www.doi.org/10.1016/j.livsci.2009.08.001 
Maya-Soriano MJ, López-Gatius F, Andreu-Vázquez C, and López-Béjar M (2013). Bovine Oocytes Show a Higher Tolerance to Heat Shock in the Warm Compared with the Cold Season of the Year. Theriogenology, 79(2): 299-305. DOI: https://www.doi.org/10.1016/j.theriogenology.2012.08.020

Mesbah F, Kafi M, and Nili H (2016). Cumulus cell expansion and first polar body extrusion during in vitro oocyte maturation in relation to morphological and morphometric characteristics of the dromedary camel ovary. Reproduction Domestic Animals, 51(6): 916-923. DOI: https://www.doi.org/10.1111/rda.12758

Moulavi F, and Hosseini SM (2018). Diverse patterns of cumulus cell expansion during in vitro maturation reveal heterogeneous cellular and molecular features of oocyte competence in dromedary camel. Theriogenology, 119: 259-267. DOI: https://www.doi.org/10.1016/j.theriogenology.

Nabenishi H, Ohta H, Nishimoto T, Morita T, Ashizawa K, and Tsuzuki Y (2012). The effects of cysteine addition during in vitro maturation on the developmental competence, ROS, GSH and apoptosis level of bovine oocytes exposed to heat stress. Zygote, 20(3): 249-259. DOI: https://doi.org/www.10.1017/S0967199411000220

Oseni S, Misztal I, Tsuruta S, and Rekaya R (2003). Seasonality of days open in US Holsteins. Journal of Dairy Science, 86: 37183725. DOI: https://www.doi.org/10.3168/jds.S0022-0302(03)73977-0

Pöhland R, Souza-Cácares MB, Datta TK, Vanselow J, Martins MIM, da Silva WAL, Cardoso CJT, and Melo-Sterza FA (2020). Influence of long-term thermal stress on the in vitro maturation on embryo development and Heat Shock Protein abundance in zebu cattle. Animal Reproduction, 17(3): e20190085. DOI: https://www.doi.org/10.1590/1984-3143-ar2019-0085

Rabie TSKM (2020). Potential Climate Change Impacts on Livestock and Food Security Nexus in Egypt. In: Ewis Omran ES, Negm A. (eds) Climate Change Impacts on Agriculture and Food Security in Egypt. Springer Water. Springer, Cham, pp. 423-450. DOI: https://www.doi.org/10.1007/978-3-030-41629-4_17

Roth Z (2017). Effect of Heat Stress on Reproduction in Dairy Cows: Insights into the Cellular and Molecular Responses of the Oocyte. Annual Review of Animal Biosciences, 8(5): 151-170. DOI: https://www.doi.org/10.1146/annurev-animal-022516$\underline{022849}$

Saadeldin IM, Swelum AA, Elsafadi M, Mahmood A, Yaqoob SH, Alfayez M, and Alowaimer AN (2019). Effects of all-trans retinoic acid on the in vitro maturation of camel (Camelus dromedarius) cumulus-oocyte complexes. Journal of Reproduction and Development, 14(3): 215-221. DOI: https://www.doi.org/10.1262/jrd.2018-073

Saadeldin IM, Swelum AA-A, Elsafadi M, Mahmood A, Alfayez M, and Alowaimer AN (2018). Differences between the tolerance of camel oocytes and cumulus cells to acute and chronic hyperthermia. Journal of Thermal Biology, 74: 47-54. DOI: https://www.doi.org/10.1016/j.jtherbio.2018.03.014

Sadeesh EM, Sikka P, Balhara AK, and Balhara S (2016). Developmental Competence and Expression Profile of Genes in Buffalo (Bubalus Bubalis) Oocytes and Embryos Collected Under Different Environmental Stress. Cytotechnology, 68(6): 22712285. DOI: https://www.doi.org/10.1007/s10616-016-0022-y

Snedecor GW, and Cochran WG (1994). Statistical Methods. 9th Ed., Iowa State Univ. Press, Ames, Iowa, USA, Available at: https://journals.sagepub.com/doi/abs/10.3102/10769986019003304

Tibary A, and El Allali K (2020). Dromedary camel: A model of heat resistant livestock animal. Theriogenology, 154: 203-211. DOI: https://doi.org/10.1016/j.theriogenology.2020.05.046

Trasorras V, Giuliano S, and Miragaya M (2013). In vitro production of embryos in South American Camelids. Animal Reproduction Science, 136: 187-193. DOI: https://www.doi.org/10.1016/j.anireprosci.2012.10.009

Wani NA (2007). Chemical activation of in vitro matured dromedary camel (Camelus dromedarius) oocytes: Optimization of protocols. Theriogenology, 69: 591-602. DOI: https://www.doi.org/10.1016/j.theriogenology.2007.11.011

Wolfenson D, Flamenbaum I, and Berman A (1988). Dry period heat stress relief effects on prepartum progesterone, calf birth weight and milk production. Journal of Dairy Science, 71: 809-818. DOI: https://www.doi.org/10.3168/jds.S0022-0302(88)79621-6

Wolfenson, D, Roth Z, and Meidan R (2000). Impaired reproduction in heat-stressed cattle: Basic and applied aspects. Animal Reproduction Science, 60-61: 535-547. DOI: https://www.doi.org/10.1016/S0378-4320(00)00102-0

Yaqoob SH, Saadeldin IM, Swelum AA-A, and Alowaimer AN (2017). Optimizing camel (Camelus dromedarius) oocytes in vitro maturation and early embryo culture after parthenogenetic activation. Small Ruminants Research, 153: 81-86. DOI: https://www.doi.org/10.1016/j.smallrumres.2017.05.011

Yaqoob, Hilal S, Saadeldin, Islam M, Swelum, Ayman A, Al-Owaimer, and Abdullah N (2017). Optimizing camel (Camelus dromedarius) oocytes in vitro maturation and early embryo culture after parthenogenetic activation. Small Ruminant Research, DOI: https://www.dx.doi.org/10.1016/j.smallrumres.2017.05.011. 